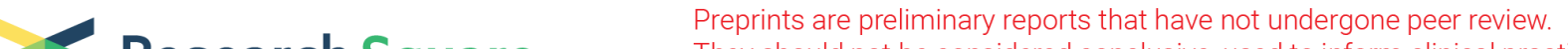 Research Square They should not be considered conclusive, used to inform clinical practice, or referenced by the media as validated information.
}

\section{The Inhibition Efficiency of Blue Light And Light Intensity On The Growth Rate of Microcystis Aeruginosa}

Shunsuke Watanabe ( $\nabla$ s.watanabe1014744@gmail.com )

Kyushu University: Kyushu Daigaku https://orcid.org/0000-0003-1151-3787

Naoki Matsunami

Kyushu University: Kyushu Daigaku

Ikki Ookuma

Kyushu University: Kyushu Daigaku

Tannen Naythen Podiapen

Central Water Authority

Megumu Fujibayashi

Kyushu University: Kyushu Daigaku

Yasushi Iseri

Wenzhou University

Aimin Hao

Wenzhou University

Takahiro Kuba

Kyushu University: Kyushu Daigaku

\section{Research Article}

Keywords: Blue light, Cyanobacteria, Diatom, LED, Water blooms

Posted Date: July 23rd, 2021

DOI: https://doi.org/10.21203/rs.3.rs-620801/v1

License: (c) (i) This work is licensed under a Creative Commons Attribution 4.0 International License. Read Full License 


\section{Abstract}

Lake eutrophication is associated with the occurrence of cyanobacterial blooms which have a negative effect on other organisms. Several studies demonstrated that blue LED irradiation inhibits the growth rate of cyanobacteria Microcystis aeruginosa, while the efficiency varies from study to study. In this paper, the focus was on the effects of light intensity on the growth of $M$. aeruginosa because the light intensity used in the precious studies varied from 12 to $45 \mu \mathrm{mol}$ photons $\mathrm{m}^{-2} \mathrm{~s}^{-1}$. Growth experiment of $M$. aeruginosa was conducted with $32 \mu \mathrm{mol}$ photons $\mathrm{m}^{-2} \mathrm{~s}^{-1}$ blue light and fluorescent light, and the results were compared with the findings of previous reports. Furthermore, co-culture of $M$. aeruginosa and diatom Nitzschia palea was also prepared. The growth rate of $M$. aeruginosa was 0.33 day $^{-1}$ and 0.11 day $^{-1}$ under fluorescent light and blue light, respectively. The blue light dropped the growth rate by $67 \%$. Compared with previous studies, the inhibition efficiency seemed to be the best at $20 \mu \mathrm{mol}$ photons $\mathrm{m}^{-2} \mathrm{~s}^{-1}$. The growth rate of N. palea was 0.62 day $^{-1}$ and 0.36 day $^{-1}$ under fluorescent light and blue light, respectively. Since the efficiency of $N$. palea by blue light (42\%) was smaller than that of $M$. aeruginosa, blue light is considered to be a countermeasure to cyanobacterial blooms.

\section{Introduction}

Lake eutrophication is one of the most serious environmental problems around the world (Bhagowati \& Ahamad 2019) and is associated with the occurrence of water blooms (O'neil et al. 2012). The increase of atmospheric $\mathrm{CO}_{2}$ gas concentration promotes the growth of cyanobacteria Microcystis aeruginosa (Ma et al. 2019). Consequently, the occurrence of water blooms will increase around the world due to global warming.

Water blooms have a negative impact on various organisms. For instance, fish are killed because of oxygen depletion caused by cyanobacterial respiration during night time and the clogging of their gills (Jewel et al. 2003). Other examples include the inhibition of photosynthesis of aquatic plants due to shading (Casanova et al. 1999) and loss of algal biodiversity owing to the dominance of Microcystis (Magrann et al. 2012). Furthermore, they can produce odorous substances such as 2-Methylisoborneol (MIB) and geosmin, and harmful compounds known as microcystin and anatoxin (Izaguirre et al. 1982; Watanabe et al. 1988; Edwards et al. 1992).

The growth of cyanobacteria is related to environmental conditions such as $\mathrm{pH}$, temperature and nutrients. Moreover, the interspecific interactions are key to whether cyanobacteria become the predominant species in aquatic ecosystems. For instance, $M$. aeruginosa suppressed the growth of green algae Scenedesmus obliquus at $\mathrm{pH}$ 7-9, whereas the growth of $M$. aeruginosa declined in co-culture with $S$. obliquus at $\mathrm{pH} \leqq 6$ compared with a monoculture (Yang et al. 2018). Zhang et al. (2013) reported that green algae Quadrigula chodatii has a strong inhibitory effect on the growth of $M$. aeruginosa above $25^{\circ} \mathrm{C}$. Amano and Machida (2013) reported that the co-culture with the three species at $\mathrm{PO}_{4}-\mathrm{P}=0.5 \mathrm{mgL}^{-1}$ led to the predominance of $M$. aeruginosa, while Scenedesmus quadricauda completely dominated at $\mathrm{PO}_{4}-\mathrm{P}=0.1 \mathrm{mgL}^{-1}$. Benthic diatom Nitzschia palea had better growth performance than $M$. aeruginosa in high nitrogen concentration medium, while $N$. palea did not to exert inhibition effects in lake water which had less nutrients than the growth medium (Watanabe et al. 2019). Thus, algal species competing with M. aeruginosa do not always inhibit the 
growth of $M$. aeruginosa. In order for green algae and diatom to exert inhibition effects on the growth of $M$. aeruginosa, it is effective to artificially provide a good environment, in which they have a competitive advantage over $M$. aeruginosa.

Irradiation of blue light is known to promote the growth inhibition effects on cyanobacteria such as $M$. aeruginosa. Wyman and Fay (1986) reported that the growth rate of seven strains of cyanobacteria depends on the wavelength of light. The growth rate of $M$. aeruginosa under blue light $\left(0.072\right.$ day $\left.^{-1}\right)$ was lower than that under fluorescent light $\left(0.135\right.$ day $\left.^{-1}\right)$, meaning that the growth rate decreased by about $47 \%$ by changing the irradiation light colour. Tan et al. (2020) reported that the growth rate of $M$. aeruginosa decreased by about $24 \%$ by changing the light colour from fluorescent light to blue light. Watanabe et al. (2019) reported that the growth rate under fluorescent light and blue light was 0.27 day $^{-1}$ and 0.00 day $^{-1}$, respectively. Although these studies demonstrated the inhibition effects of blue light on the growth rate of cyanobacteria, the inhibition efficiency varied from study to study. It is important for the application of the blue light in field conditions to identify the factor which affected inhibition efficiency of blue light on cyanobacterial growth.

In this paper, we focused on the effects of light intensity on cyanobacterial growth because the light intensity used in the previous studies varied from 12 to $45 \mu \mathrm{mol}$ photons $\mathrm{m}^{-2} \mathrm{~s}^{-1}$. We conducted the growth experiment of $M$. aeruginosa with $32 \mu \mathrm{mol}$ photons $\mathrm{m}^{-2} \mathrm{~s}^{-1}$ blue light and fluorescent light, and compared the results with the previous reports. Furthermore, in preparation for the co-culture with $M$. aeruginosa, $N$. palea was also cultivated.

\section{Materials And Methods}

\section{Algae cultivation}

M. aeruginosa NIES-102 was obtained from The National Institute for Environmental Studies (NIES), Ibaraki, Japan. N. palea was isolated from Fujinohira dam, Saga Prefecture, Japan in 2015 where water blooms were present. $N$. palea was identified through an electron microscopic observation. Both species were cultivated in a WC medium (Guillard \& Lorenzen 1972) at pH 8.0 autoclaved at $121^{\circ} \mathrm{C}$ for $30 \mathrm{~min}$, which was also used in all experiments. The incubates were performed at $25^{\circ} \mathrm{C}, 32 \mu \mathrm{mol}$ photons $\mathrm{m}^{-2} \mathrm{~s}^{-1}$, light-dark cycle of 12:12, and shaken once daily.

The effects of blue light irradiation on the monoculture of $\mathrm{M}$. aeruginosa and N. palea

M. aeruginosa and N. palea were inoculated individually in $150 \mathrm{~mL}$ medium in a $300-\mathrm{mL}$ Erlenmeyer flask, with an initial cell density of 4,000 cells $\mathrm{mL}^{-1}$ for each species. Algae were irradiated with a $3 \mathrm{~W}$ blue LED (KASHINOKI SOGYO Co. Ltd., Tokyo, Japan) and fluorescent light (as the control) at $32 \mu \mathrm{mol}$ photons $\mathrm{m}^{-2} \mathrm{~s}^{-}$

${ }^{1}$, which is was not specifically assessed in the previous studies (Wyman and Fay, 1986; Watanabe et al. 2019; Tan et al. 2020). The light -dark cycle was $12: 12$. This experiment was conducted in triplicate at $25^{\circ} \mathrm{C}$ until the stationary growth phase.

\section{Analysis}


By vigorous manual shaking and pipetting, $N$. palea was separated from the substrate and collected using a sterilized glass pipette. $M$. aeruginosa was collected without vigorous shaking. Cell density was counted every 2 or 3 days by using Optical Plastic Plankton Counters (Matsunami Glass Industry, Osaka, Japan) and a microscope (Olympus, BH2-RFCA). Using the cell density during the exponential growth phases, the specific growth rate was obtained by using the Eq. (1), where $\mu$ represents specific growth rate (day $\left.{ }^{-1}\right), C_{1}$ and $C_{2}$ represent the cell density (cells $\mathrm{mL}^{-1}$ ) of $M$. aeruginosa and $N$. palea at the culture time of $t_{1}$ and $t_{2}$ (day), respectively.

$\mu=1 /\left(t_{2}-t_{1}\right) \ln C_{2} / C_{1}(1)$

A Student's t-test was carried out to compare the differences in the specific growth rate and the maximum cell yields in the monoculture between fluorescent light and blue light irradiated at $32 \mu \mathrm{mol}$ photons $\mathrm{m}^{-2} \mathrm{~s}^{-1}$.

\section{Results}

The effects of blue light irradiation on the monoculture of $\mathrm{M}$. aeruginosa and $\mathrm{N}$. palea

M. aeruginosa grew under fluorescent light until the end of the experiment and the growth rate was 0.33 day $^{-}$ ${ }^{1}$, while they hardly grew under blue light. Exponential growth under blue light was observed up to day 8 (Fig. 1) and the growth rate was 0.11 day $^{-1}$ which was significantly lower than that of fluorescent light (Student's t-test, $p$ <0.01). N. palea could grow under both light conditions. The specific growth rate for $N$. palea under fluorescent light $\left(0.62 \mathrm{day}^{-1}\right)$ was higher than that under blue light that was 0.36 day $^{-1}$ (Student's t-test, $p<0.01$ ). No significant difference was observed in the maximum cell yields of $N$. palea under fluorescent light and blue light (Student's t-test, $p>0.05$ ).

Figure2 shows the growth rate obtained from each light intensity, including the previous studies, and Table1 shows each experimental condition. The growth rate for $M$. aeruginosa under fluorescent light showed an upward trend as the light intensity increased in the range of to $32 \mu \mathrm{mol}$ photons $\mathrm{m}^{-2} \mathrm{~s}^{-1}$ and the growth rate at $45 \mu \mathrm{mol}$ photons $\mathrm{m}^{-2} \mathrm{~s}^{-1}$ was about the same as at $32 \mu \mathrm{mol}$ photons $\mathrm{m}^{-2} \mathrm{~s}^{-1}$. Under blue light, the growth rate was 0.11 day $^{-1}$ at $32 \mu \mathrm{mol}$ photons $\mathrm{m}^{-2} \mathrm{~s}^{-1}$. It was zero at $20 \mu \mathrm{mol}$ photons $\mathrm{m}^{-2} \mathrm{~s}^{-1}$ and was greater than zero at other light intensity. The growth rate for $N$. palea at $32 \mu \mathrm{mol}$ photons $\mathrm{m}^{-2} \mathrm{~s}^{-1}$ was higher than that at $20 \mu \mathrm{mol}$ photons $\mathrm{m}^{-2} \mathrm{~s}^{-1}$ under both light conditions.

Table 1 Culture conditionsof this study and the previous studies 


\begin{tabular}{|lllll|}
\hline $\begin{array}{l}\text { Light intensity } \\
\left(\mu \mathrm{mol} \text { photons } \mathbf{~ m}^{-2}\right.\end{array}$ & $\begin{array}{l}\text { Light-dark } \\
\text { cycle }\end{array}$ & $\begin{array}{l}\text { Temperature } \\
\mathbf{s}^{-1} \text { ) }\end{array}$ & Medium & Reference \\
\hline 12 & $16: 08$ & 20 & $\begin{array}{l}\text { BG-11 } \\
\text { (diluted to } 5 \% \text { by } \\
\text { volume) }\end{array}$ & $\begin{array}{l}\text { Wyman and Fay } \\
(1986)\end{array}$ \\
\hline 20 & $24: 0$ & 25 & WC & $\begin{array}{l}\text { Watanabe et al. } \\
(2019)\end{array}$ \\
\hline 32 & $12: 12$ & 25 & WC & This study \\
\hline 45 & $12: 12$ & 25 & BG-11 & Tan et al. (2020) \\
\hline
\end{tabular}

\section{Discussion}

The growth curves of $M$. aeruginosa were significantly different under fluorescent and blue light. The specific growth rate for $M$. aeruginosa under fluorescent light $\left(0.33\right.$ day $\left.^{-1}\right)$ was consistent with the one that Ohkubo et al. (1991) obtained from the same strain cultivated under similar conditions $\left(0.32\right.$ day $\left.^{-1}\right)$. Compared with the results under the fluorescent light, the growth of $M$. aeruginosa was inhibited under blue light, and this result was in line with the previous studies (Wyman and Fay 1986; Watanabe et al. 2019; Tan et al. 2020). Luimstra et al. (2018) has reported that when phycobilisome-containing cyanobacteria Synechocystis sp. absorbed blue light and the efficiency of oxygenic photosynthesis and growth declined because of phycobilisomes. They can absorb light in the red range and work as accessory pigments to compensate for the deficiency of photons in photosystem $\otimes$ under red LED. However, they cannot absorb light in the blue range, which created an imbalance in the electron transport energy between two photosystems under blue LED. Since M. aeruginosa contains phycobilisomes (Raps et al. 1985), it is considered that its growth was suppressed like Synechocystis sp.

The degree of the inhibition effects on the growth of $M$. aeruginosa by blue light differed among the studies. As shown in Table 1, the culture conditions were not consistent among each experiment. For instance, Wyman and Fay (1986) and Tan et al. (2020) used BG-11 medium at different concentration, suggesting available nutrient concentrations must have differed among the studies. It is known that the growth rate follows the Droop equation, which is a model that depends on the intracellular content, and the nutrient uptake rate is calculated by the Michaelis-Menten equation which depends on the nutrient concentration in the medium (Ducobu et al. 1998; Mikawa et al. 2016). Since the half-saturation constant for nutrient uptake is usually smaller than the concentration of the medium, it is considered that the growth rate does not differ depending on the type of the medium unless the nutrient is depleted. Li et al. (2014) demonstrated that there was no significant difference in the growth rate even when the medium with different nutrient concentration was used.

Temperature is also known to affect the growth of algae. It has been reported that the growth rate of $M$. aeruginosa increases with increasing temperature (You et al., 2018; Imai et al., 2009). Li et al. (2014) 
demonstrated that the growth rate of $M$. aeruginosa was higher at $25^{\circ} \mathrm{C}$ than that at $20{ }^{\circ} \mathrm{C}$. Therefore, the growth rate obtained by Wyman and Fay (1986) is expected to increase further when performed at $25^{\circ} \mathrm{C}$ (as in this experiment). The light-dark cycle used in the culture is not the same. According to the experimental data by Zevenboom and Mur (1984), The growth rate of $M$. aeruginosa is about the same in the 12:12 and 24:0 light-dark cycles. Furthermore, the difference in growth rate due to different light-dark cycles is smaller under the light intensity which is insufficient to cause saturation with respect to the growth rate. As shown in Fig. 2, the blue light intensity such as 10,20 , and $32 \mu \mathrm{mol}$ photons $\mathrm{m}^{-2} \mathrm{~s}^{-1}$ are not considered to have the intensity to cause saturation. If the relationship between the light-dark cycle and the growth rate is similar to that of fluorescent light, the difference in the growth rate under the blue light at different light-dark cycles is presumed to be small.

The growth rate may vary depending on the strain. Despite being cultivated under the same experimental conditions, which was in BG-11 at $25^{\circ} \mathrm{C}$ under fluorescent light at $45 \mu \mathrm{mol}$ photons $\mathrm{m}^{-2} \mathrm{~s}^{-1}$, the growth rates of M. aeruginosa obtained from Li et al. (2014) and Tan et al. (2020) were different, indicating 0.60 day $^{-1}$ and about 0.32 day $^{-1}$, respectively. On the other hand, the strain used in this study and Watanabe et al. (2019) were the same. The growth rate under blue light was zero at $20 \mu \mathrm{mol}$ photons $\mathrm{m}^{-2} \mathrm{~s}^{-1}$ (Watanabe et al. 2019), while that at $32 \mu \mathrm{mol}$ photons $\mathrm{m}^{-2} \mathrm{~s}^{-1}$ was 0.11 day $^{-1}$. Since the effect of the light-dark cycle can be assumed to be small, the increase in the growth rate of $M$. aeruginosa was due to the increase in the light intensity. The growth rate may vary depending on the strain, however, it is expected that the growth rate will increase as the blue light intensity increases. Overall, the observed difference in the growth rate of $M$. aeruginosa is determined by the light intensity. As shown in Fig. 2 , it is considered that the growth rate tends to be at its minimum when the blue light intensity is around $20 \mu \mathrm{mol}$ photons $\mathrm{m}^{-2} \mathrm{~s}^{-1}$.

The specific growth rate for $N$. palea under fluorescent light $\left(0.62\right.$ day $\left.^{-1}\right)$ was higher than that under blue light $\left(0.36\right.$ day $\left.^{-1}\right)$. It was previously reported that the specific growth rate under blue light $\left(0.23\right.$ day $\left.^{-1}\right)$ was higher than under fluorescent light, which was 0.21 day $^{-1}$ (Watanabe et al. 2019). The difference of the specific growth rate under each light condition between the previous and current study is likely due to the difference in light intensity. Figure 2 indicates that the increase in the specific growth rate for N. palea in a light intensity was higher in fluorescent light than in blue light. The results showed that $N$. palea grew under blue light while $M$. aeruginosa did not, which was the same as the previous study for all conditions (Watanabe et al. 2019). Diatoms have a fucoxanthin which is a natural pigment (Wang et al. 2018). The adsorption of the fucoxanthins is optimal in the range of $480-560 \mathrm{~nm}$, although there is some light absorption in the range of $420-470 \mathrm{~nm}$, which represents the blue wavelength (Papagiannakis et. al. 2005). Similarly, Ohgai et al. (1992) reported diatom Cocconeis sp. grew drastically better in blue fluorescent light. Therefore, the growth of $N$. palea in blue light was promoted by fucoxanthin. However, the growth rate of $N$. palea under blue light at $32 \mu \mathrm{mol}$ photons $\mathrm{m}^{-2} \mathrm{~s}^{-1}$ did not increase significantly. A fucoxanthin assists the growth of $N$. palea under blue light, but it may be slow to respond to increased light intensity. It should also be noted that no significant differences were detected in maximum cell yields between fluorescent and blue light conditions. 
In order to provide a good environment in which $N$. palea has a competitive advantage over M. aeruginosa, it is important to irradiate blue light at the intensity that can inhibit the growth rate of $M$. aeruginosa while promoting that of $N$. palea. The blue light intensity at $20 \mu \mathrm{mol}$ photons $\mathrm{m}^{-2} \mathrm{~s}^{-1}$ is ideal as the growth rate of $M$. aeruginosa is zero while $N$. palea can still grow. When fluorescent light was replaced by blue light at 32 $\mu \mathrm{mol}$ photons $\mathrm{m}^{-2} \mathrm{~s}^{-1}$, the growth rate of $M$. aeruginosa changed from 0.33 to 0.11 day $^{-1}$, meaning that the growth rate dropped by $67 \%$ while that of $N$. palea dropped by only $42 \%$. Therefore, it is considered that blue light irradiation was useful in inhibiting the growth of $M$. aeruginosa, indicating that M. aeruginosa was in relatively disadvantageous conditions.

\section{Conclusion}

The inhibition efficiency of blue light on the growth rate of $M$. aeruginosa was related to the light intensity. The best light intensity was $20 \mu \mathrm{mol}$ photons $\mathrm{m}^{-2} \mathrm{~s}^{-1}$. It is considered that blue light irradiation could be a countermeasure to water blooms since the growth of $M$. aeruginosa was affected by the conditions.

\section{Declarations}

\section{Ethics approval and consent to participate}

Not applicable for us.

\section{Consent for publication}

Not applicable for us.

\section{Availability of data and materials}

The datasets during and/or analysed during the current study available from the corresponding author on reasonable request.

\section{Competing interests}

The authors declare that they have no competing interests.

\section{Funding}

No funding was received.

\section{Author's contributions}

NM and IO prepared to do experiment such as making a medium, subculture of algae etc. PTN who had helped isolate Nitzschia proofread the English text. MF and TK were major contributor in writing the manuscript. $\mathrm{AH}$ and $\mathrm{YI}$ advised me on how to experiment. All authors read and approved the final manuscript.

\section{References}


1. Amano, Y., and Machida, M. (2013) Mechanisms of algal species dominance among cyanobacteria, diatoms and green algae as a consequence of phosphorus reduction caused by river water dilution in eutrophic lake. J Wat Environ Techno/ 11(5), 391-401. https://doi.org/10.2965/jwet.2013.391

2. Bhagowati, B. and Ahamad, K.U. (2019) A review on lake eutrophication dynamics and recent developments in lake modeling. Ecohydrol Hydrobiol 19, 155-166.

https://doi.org/10.1016/j.ecohyd.2018.03.002

3. Casanova, M.T., Burch, M.D., Brock, M.A. and Bond, P.M. (1999) Does toxic Microcystis aeruginosa affect aquatic plant establishment?. Environ Toxico/ 14, 97-109. https://doi.org/10.1002/(SICI)15227278(199902)14:1\%3c97::AID-TOX13\%3e3.0.C0;2-3

4. Ducobu, H., Huisman, J., Jonker, R.R. and Mur, L.R. (1998) Competition between a prochlorophyte and a cyanobacterium under various phosphorus regimes: comparison with the droop model. J Phyco/34, 467-576. https://doi.org/10.1046/j.1529-8817.1998.340467.x

5. Edwards, C., Beattie, K.A., Scrimgeour, C.M. and Codd, G.A. (1992) Identification of anatoxin-a in benthic cyanobacteria (blue-green-algae) and in associated dog poisonings at Loch Insh, Scotland. Toxicon 30(10), 1165-1175. https://doi.org/10.1016/0041-0101(92)90432-5

6. Guillard, R.R.L and Lorenzen, C.J (1972) Yellow-green algae with chlorophyllide. J Phycol 8, 10-14. https://doi.org/10.1111/j.1529-8817.1972.tb03995.x

7. Imai H., Chang K.H., Kusaba, M. and Nakano S. (2009) Temperature-dependent dominance of Microcystis (Cyanophyceae) species: M. aeruginosa and M. wesenbergii. J Plankton Res 31(2), 171178. https://doi.org/10.1093/plankt/fbn110

8. Izaguirre, G., Hwang, C.J., Krasner, S.W. and Mcguire, M.J. (1982) Geosmin and 2-Methylisoborneol from cyanobacteria in three water supply systems. Appl Environ Microbio/ 43(3), 708-714. https://doi.org/10.1128/AEM.43.3.708-714.1982

9. Jewel, M.A.S., Affan, M.A. and Khan, S. (2003) Fish mortality due to cyanobacterial bloom in an aquaculture pond in Bangladesh. Pki J Biol Sci 6(12), 1046-1050.

https://doi.org/10.3923/pjbs.2003.1046.1050

10. Li, M., Nkrumah, P.N. and Xiao, M. (2014) Biochemical composition of Microcystis aeruginosa related to specific growth rate: insight into the effects of abiotic factors. Inland Waters 4, 357-362. https://doi.org/10.5268/IW-4.4.710

11. Luimstra, V.M., Schuurmans, J.M., Verschoor, A.M., Hellingwerf, K.J., Huisman, J. and Matthijs, H.C.P. (2018) Blue light reduces photosynthetic efficiency of cyanobacteria through an imbalance between photosystems I and II. Photosynth Res 138, 177-189. https://doi.org/10.1007/s11120-018-0561-5

12. Ma, J., Wang, P., Wang, X., Xu, Y. and Paerl, H.W. (2019) Cyanobacteria in eutrophic waters benefit from rising atmospheric $\mathrm{CO}_{2}$ concentrations. Sci Total Environ 691, 1144-1154. https://doi.org/10.1016/j.scitotenv.2019.07.056

13. Magrann, T., Dunbar, S.G., Boskovic, D.S. and Hayes, W.K. (2012) Impacts of Microcystis on algal biodiversity and use of new technology to remove Microcystis and dissolved nutrients. Lakes Reservoirs Res Manage 17, 231-239. https://doi.org/10.1111//re.12000 
14. Mikawa, M., Sugimoto, K., Amano, Y., Machida, M. and Imazeki, F. (2016) Competitive growth characteristics between Microcystis aeruginosa and Cyclotella sp. Accompanying changes in river water inflow and their simulation model. Phycol Res 64, 123-132. https://doi.org/10.1111/pre.12129

15. Ohgai, M., Matsi, T. and Takagi, H. (1992) The effect of the environmental factors on the growth of attached diatom Cocconeis sp. Suisanzoshoku 40(2), 241-246. (in Japanese with English summary) https://doi.org/10.11233/aquaculturesci1953.40.241

16. Ohkubo, N., Yagi, O. and Okada, M. (1991) Effects of temperature and illumination on the growth of bluegreen alga Microcystis viridis. Jpn J Limno/ 52(4), 255-261. https://doi.org/10.3739/rikusui.52.255

17. O’Neil, J.M., Davis, T.W., Burford, M.A. and Gobler, C.J. (2012) The rise of harmful cyanobacteria blooms: The potential roles of eutrophication and climate change. Harmful Algae 14, 313-334. https://doi.org/10.1016/j.hal.2011.10.027

18. Papagiannakis, E., van Stokkum, I.H.M., Fey, H., Buchel, C. and van Grondelle, R. (2005) Spectroscopic characterization of the excitation energy transfer in the fucoxanthin-chlorophyll protein of diatoms. Photosynth Res 86, 241-250. https://doi.org/10.1007/s11120-005-1003-8

19. Raps, S., Kycia, J.H., Ledbetter, M.C. and Siegelman, H.W. (1985) Light intensity adaptation and phycobilisome composition of Microcystis aeruginosa. Plant Physiol 79, 983-987. https://doi.org/10.1104/pp.79.4.983

20. Tan, X., Zhang, D., Duan, Z., Parajuki, K. and Hu, J. (2020) Effects of light color on interspecific competition between Microcystis aeruginosa and Chlorella pyrenoidosa in batch experiment. Environ Sci Pollut Res 27(1), 344-352. https://doi.org/10.1007/s11356-019-06650-5

21. Wang, L.J., Fan, Y., Parsons, R.L., Hu, G.R., Zhang, P.Y. and Li, F.L. (2018) A rapid method for the determination of fucoxanthin in diatom. Mar Drugs 16(33), 1-13. https://doi.org/10.3390/md16010033

22. Watanabe, M.F., Oishi, S., Harada, K., Matsuura, K., Kawai, H. and Suzuki, M. (1988) Toxins contained in Microcystis species of cyanobacteria (blue-green algae). Toxicon 26(11), 1017-1025. https://doi.org/10.1016/0041-0101(88)90200-0

23. Watanabe, S., Podiapen, T.N., Itose, R., Iseri, Y., Hao, A. and Kuba, T. (2019) The competition characteristic of diatom Nitzschia palea and water blooms and the growth inhibition effect of LED irradiation on cyanobacteria Microcystis aeruginosa. J Jpn Soc Civil Eng Ser G (Environ Res) 75(7), III_97-III_105. (in Japanese with English summary) https://doi.org/10.2208/jscejer.75.7_III97

24. Wyman, M. and Fay, P. (1986) Underwater light climate and the growth and pigmentation of planktonic blue-green-algae (Cyanobacteria) II. The influence of light quality. Proc Royal Soc Ser B 227(1248), 381393. https://doi.org/10.1098/rspb.1986.0028

25. Yang, J., Tang, H., Zang, X., Zhu, X., Huang, Y. and Yang, Z. (2018) High temperature and pH favor Microcystis aeruginosa to outcompete Scenedesmus obliquus. Environ Sci Pollut Res 25, 4794-4802. https://doi.org/10.1007/s11356-017-0887-0

26. You, J., Mallery, K., Hong, J. and Hondzo, M. (2018) Temperature effects on growth and buoyancy of Microcystis aeruginosa. J Plankton Res 40(1), 16-28. https://doi.org/10.1093/plankt/fbx059

27. Zevenboom, W., and Mur L.R. (1984) Growth and photosynthetic response of the cyanobacterium Microcystis aeruginosa in relation to photoperiodicity and irradiance. Arch Microbiol 139, 232-239. 
https://doi.org/10.1007/BF00402006

28. Zhang, P., Zhai, C., Wang, X., Liu, C., Jiang, J. and Xue, Y. (2013) Growth competition between Microcystis aeruginosa and Quadrigula chodatii under controlled conditions. J Appl Phycol 25, 555-565. https://doi.org/10.1007/s10811-012-9890-5

\section{Figures}

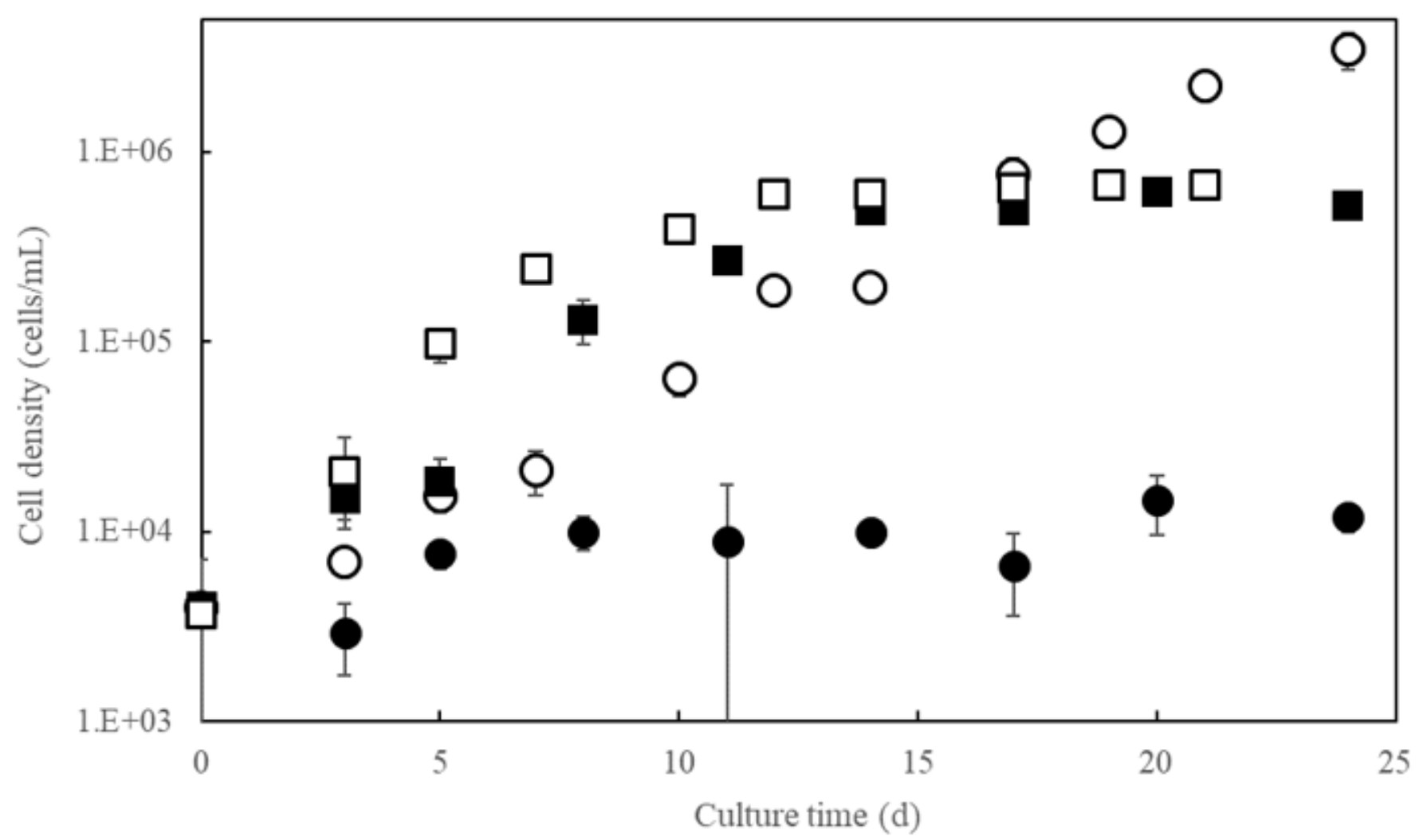

\section{Figure 1}

Change in cell density of M. aeruginosa and N. palea with time in monoculture under fluorescent light or blue light irradiation. Symbols: M. aeruginosa (fluorescent light), $\bigcirc$ M. aeruginosa (blue light), $\square$ N. palea (fluorescent light), $\square$ N. palea (blue light)
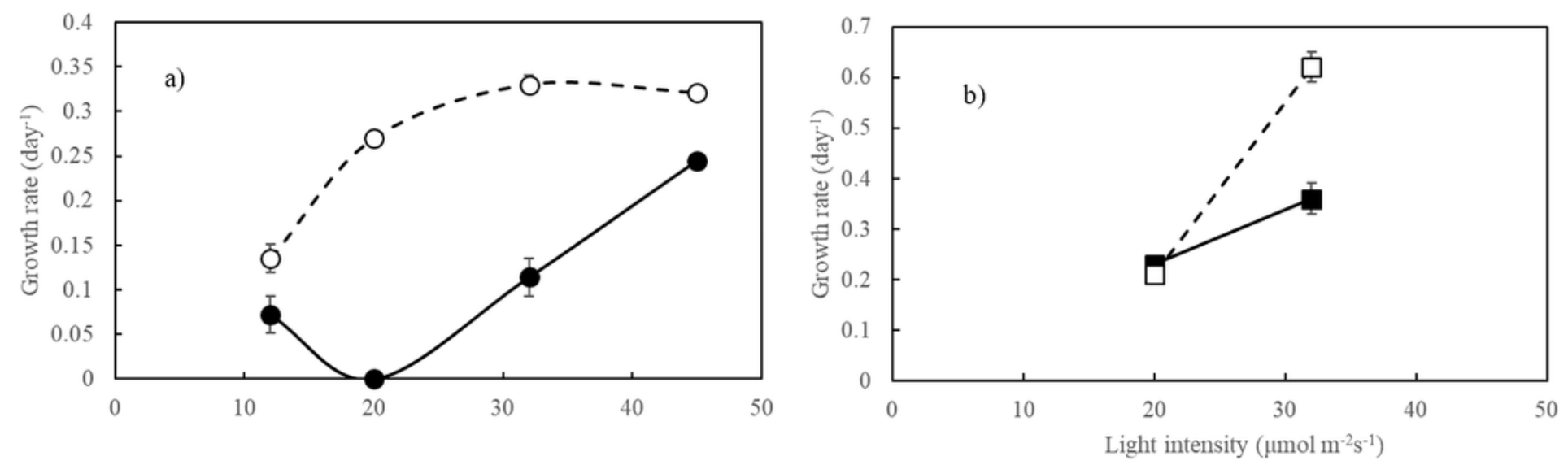


\section{Figure 2}

The growth rate for a) M. aeruginosa b) N. palea at each light intensity of fluorescent light and blue light. Symbols: M. aeruginosa (fluorescent light), M. aeruginosa (blue light), $\square$ N. palea (fluorescent light), N. palea (blue light). The growth rate at 12, 20, $45 \mu$ mol photons m-2 s-1 was obtained from Wyman and Fay (1986), Watanabe et al. (2019), Tan et al. (2020), respectively 